\title{
Inauguração da Casa Sagrada Mau Suma - Rai Alas. Revivendo tradições e alianças em Timor-Leste
}

Inauguration of the Sacred House Mau Suma-Rai Alas. Re-living traditions and alliances in Timor-Leste

\section{Carlos Andrés Oviedo}

\section{(2) OpenEdition}

Journals

Edição electrónica

URL: https://journals.openedition.org/aa/8335

DOI: 10.4000/aa.8335

ISSN: 2357-738X

\section{Editora}

Programa de Pós-Graduação em Antropologia Social (UnB)

Edição impressa

Paginação: 215-235

ISSN: 0102-4302

\section{Refêrencia eletrónica}

Carlos Andrés Oviedo, «Inauguração da Casa Sagrada Mau Suma - Rai Alas. Revivendo tradições e alianças em Timor-Leste», Anuário Antropológico [Online], v.46 n.2 | 2021, posto online no dia 30 maio 2021, consultado o 01 junho 2021. URL: http://journals.openedition.org/aa/8335 ; DOI: https://doi.org/ 10.4000/aa.8335

\section{(c) (i) $\ominus$}

Anuário Antropológico is licensed under a Creative Commons Atribuição-Uso Não-Comercial-Proibição de realização de Obras Derivadas 4.0 International. 


\title{
anuário antropológico \\ v. $46 \cdot \mathrm{n}^{\circ} 2 \cdot \mathrm{majo-agosto} \cdot 2 \odot 21.2$
}

\section{Inauguração da Casa Sagrada Mau Suma - Rai Alas. Revivendo tradições e alianças em Timor- Leste $^{1}$}

\author{
Inauguration of the Sacred House Mau Suma - Rai Alas. Re-living traditions and \\ alliances in Timor-Leste
}

DOI: https://doi.org/10.4000/aa.8335

\section{Carlos Andrés Oviedo}

Universidade de Brasília, Instituto de Ciências Sociais, Departamento de Antropologia,

Laboratório de Estudos em Economias e Globalizações, Brasília, DF, Brasil

Antropólogo pela Universidad del Cauca, Colômbia. Doutor em Antropologia Social pela Universidade de Brasília (UnB). Faz parte do Laboratório de Estudos em Economias e Globalizações - LEEG, da mesma Universidade.

Este ensaio explora, através de uma narrativa visual, a festa de inauguração da Casa Sagrada Mau Suma - Rai Alas na aldeia de Samatrae, município de Ermera, Timor-Leste. Tal inauguração recria o valor de pertencimento a uma Casa Sagrada e a manutenção de redes de aliança através da troca de bens entre grupos ou "casas". Guiado pela voz de alguns dos filhos das "casas" que participam do evento, este ensaio busca registrar o repertório cosmológico que estrutura as relações entre pessoas, grupos e ancestrais no Timor-Leste contemporâneo. As imagens foram produzidas durante os três dias da festa de inauguração da Casa Sagrada, entre 18 e 20 de agosto de 2017.
This essay explores, through a visual narrative, the inauguration ceremony of the sacred house Mau Suma - Rai Alas in the village of Samatrae, municipality of Ermera, East Timor. This inauguration recreates the value of belonging to a sacred house and the maintenance of alliance networks through the exchange of goods amongst groups or "houses". Guided by the voice of some of the sons of the "houses" who participates in the event, this essay aims to portray the cosmological repertoire that structures the relationships amongst persons, groups, and ancestors in contemporary East Timor. The images of this essay were produced during the three days of the inauguration ceremony of the sacred house, between August 18 and 20, 2017.

Sacred House. House. East-Timor. Ritual. Alliance. 
Quase duas décadas após a restauração da independência, a República Democrática de Timor-Leste tem vivenciado uma importante revitalização de tradições e ressignificação de práticas ancestrais (Hicks, 2007; Brown, 2009; Barnes, 2016). Esses esforços cobram especial relevância se considerarmos a turbulenta história dessa nação do Sudeste Asiático, a qual tem sido marcada por sucessivas ocupações e administrações estrangeiras (colonização portuguesa, 1512-1974; invasão japonesa, 1942-1943; a ocupação Indonésia, 1975-1999; e a administração transitória das Nações Unidas, 1999-2002). Por sua importância no fortalecimento dos valores grupais e dos vínculos que unem pessoas com lugares de origem, a reconstrução da Casa Sagrada - tema deste ensaio - tem sido fundamental no restabelecimento da estrutura social do país no marco da construção do Estado-nação moderno (McWilliam, 2005). Nesta introdução apresento alguns elementos conceituais para melhor entender o papel da "casa" na sociedade timorense e a importância da Casa Sagrada ou uma-lulik - em língua tétum -enquanto construção material e simbólica².

Como em outras regiões do Sudeste Asiático, em Timor-Leste a noção de "casa" opera como categoria fundamental para designar um tipo particular de unidade social e política (Fox, 1980, p. 12). Nesse tipo de organização social, o legado composto por nomes, objetos sagrados e prerrogativas rituais contribuem com a identidade distintiva de cada uma das casas (Carsten; Hugh-Jones, 1995). A "casa", escreve Daniel Simião (2020) a propósito do observado entre os falantes da língua tokodede no município de Liquiçá, “(...) põe em ação não apenas uma cosmologia (marcada pela agência dos ancestrais no mundo e pelo respeito aos espíritos da terra), mas um sentido de lealdade, colaboração, antagonismo e/ou subordinação entre grupos de pessoas" (2020, p. 14).

A manifestação material da "casa", enquanto unidade social ou grupo de descendência, é a Casa Sagrada. Estas últimas podem ser observadas principalmente nas aldeias do interior do país; trata-se de construções que, por sua arquitetura (Foto 1), sobressaem sobre outras casas destinadas exclusivamente a moradia. Alguns dos meus interlocutores leste-timorenses descreveram a Casa Sagrada utilizando referentes que eram comuns para mim enquanto estrangeiro. Assim, a Casa Sagrada pode ser entendida como "templo tradicional", "Casa da Cultura", "local para os objetos sagrados e oração aos ancestrais". Muitas dessas construções foram queimadas durante a ocupação indonésia e as relíquias que abrigavam foram roubadas ou destruídas. Além disso, em vários lugares do país, o reassentamento de comunidades e a restrição de mobilidade pelo território foi utilizada como estratégia para desarticular focos de resistência (Gárate; Asis, 2010). Entretanto, isto não conduziu à ruptura com os valores associados às Casas. Pelo contrário, como apontado por McWilliam e Traube (2011), nos anos de luta armada, os guerrilheiros que fugiram para as montanhas evocaram a proteção dos espíritos da terra de origem para continuarem resistindo à invasão.

No contexto pós-independência, as Casas Sagradas têm sido reconstruídas nos diferentes municípios do país, demandando investimento de tempo e recursos por parte dos seus membros (Barnes, 2010). A antropóloga Renata Nogueira (2019) tem
1 A documentação do evento foi realizada no marco da pesquisa para a elaboração da tese de doutorado em antropologia social intitulada: "De quem é a terra? práticas de governo e construções de Estado em Timor-Leste" (2019), orientada por Kelly Silva. O trabalho de campo realizado entre junho de 2016 e outubro de 2017 foi possível graças às bolsas de doutorado do CNPq e CAPES (processos 141238/2014-3 e 88887.177407/2018-00) e ao apoio do Instituto Nacional de Estudos sobre Administração Institucional de Conflitos (INEAC).

2 Utilizarei o termo "casa" - escrito entre aspas - para me referir à unidade social ou grupo de descendência, e Casa Sagrada - escrita com maiúscula - para aludir à casa enquanto construção arquitetônica ou manifestação "material" da primeira. 
registrado que, como ocorre na comemoração do Dia de Finados, as inaugurações de Casas Sagradas congregam familiares, amigos e ancestrais, "permitindo assim que os vínculos com o passado sejam recordados, revividos e reelaborados". Assim mesmo, esta pesquisadora destaca que "os sentidos e a interpretação de eventos deste tipo são múltiplos e variam de acordo com o grupo linguístico e local de origem"3. E quanto ao tipo de organização dos grupos que participam da inauguração, alguns trabalhos etnográficos (Simião, 2009; Fidalgo, 2015), registram a divisão em três grupos. Em primeiro lugar, os uma-na'in ou donos da casa, como anfitriões da festa, são encarregados da recepção e acomodação dos assistentes. Os mane-foun, cuja tradução literal ao português é "homem novo", referem-se aos homens (e os seus descendentes) que se casaram com as mulheres da "casa". Por fim, estão os umane ou "homens da casa", que também inclui as esposas destes e as mulheres solteiras.

Este ensaio explora, através da narrativa visual, a inauguração da Casa Sagrada Mau Suma - Rai Alas na aldeia Samatrae, município de Ermera, localizado ao oeste do país. As imagens que o compõem foram produzidas durante os três dias da festa de inauguração entre o 18 e 20 de agosto de 2017. Consciente do potencial da fotografia como meio na produção de conhecimento antropológico, mas também da importância de explorar processos de produção visual que desafiem a autoridade etnográfica (Edwards, 2011), apresento uma experiência guiada pelo saber e pelos relatos de alguns dos participantes da inauguração. Cabe mencionar que 3 dos meus 4 interlocutores (Pedro Soares, Jose Maia, Adozindo Trinidade) acudiram à festa enquanto mane-foun, razão pela qual a narrativa construída segue a sequência das ações e das prerrogativas rituais, que, a partir da perspectiva deles, são representativas neste tipo de evento. São elas: chegada e acomodação dos grupos (Fotos 2, 3 e 4), primeiros encontros (Fotos 5 e 8), sacrifício de animais (Fotos 11 e 12), corte e repartição da carne (Fotos 13 e 14) e festa de encerramento (Foto 18).

Nas imagens destaco gestos e expressões emotivas dos participantes nos momentos de oferta e recepção de objetos. Foco também na etiqueta durante a festa e nos bens ofertados de acordo com a identificação em alguns dos grupos mencionados. Na tentativa de aproximar o leitor do ponto de vista dos participantes, cito, nas legendas que acompanham as fotografias, algumas das falas dos meus interlocutores, acerca das ações registradas ou explicações gerais acerca da liturgia do evento. Por fim, é importante destacar que a expectativa de apresentar a "cultura timorense" para pessoas de outros países motivou especialmente aos uma-na'in a propor o registro de momentos específicos do evento, quebrando em alguns momentos as restrições de acesso a lugares como o interior da Casa Sagrada (Foto 8) ${ }^{4}$.

No seu conjunto, o ensaio documenta, a partir de uma perspectiva local - e centrada em uma das facções dos participantes -, o ressurgimento das práticas ancestrais e o compromisso com as formas de sociabilidade estruturadas em torno do pertencimento à "casa"5 (Barnes, 2010; McWilliam, 2005). Inspirado em Victor Turner (1967), entendo o evento como processo ritual que permite captar as estruturas e cosmologias sociais vigentes nos campos de ação social (Peirano, 2000), neste caso orientadas à manutenção de redes de aliança através da troca de bens
3 Comunicação pessoal.

Outros registros e narrativas da inauguração teriam sido possíveis a partir de uma maior interação com os umane e os uma-na'in. Uma documentação mais ampla teria considerado, por exemplo, as diversas atividades logísticas envolvidas no evento e a sua distribuição por gênero.

5 O pertencimento à "casa", em tanto "orientação epistemológica fundamental" (Fox, 1993), manifesta-se em diversos domínios da construção do Estado moderno em Timor-Leste. Para conhecer sobre o papel das "casas" na administração de assuntos de justiça, ver Simião (2015) e Romanó (2020). Para ter uma aproximação ao papel das "casas" nos processos de resolução de conflitos de terra, ver Oviedo (2020). 
Carlos Andrés Oviedo

entre grupos. A narrativa visual busca nos aproximar do repertório cosmológico que estrutura as relações entre pessoas, "casas" e ancestrais no marco da construção do Estado-nação leste-timorense.

\section{Foto 1}

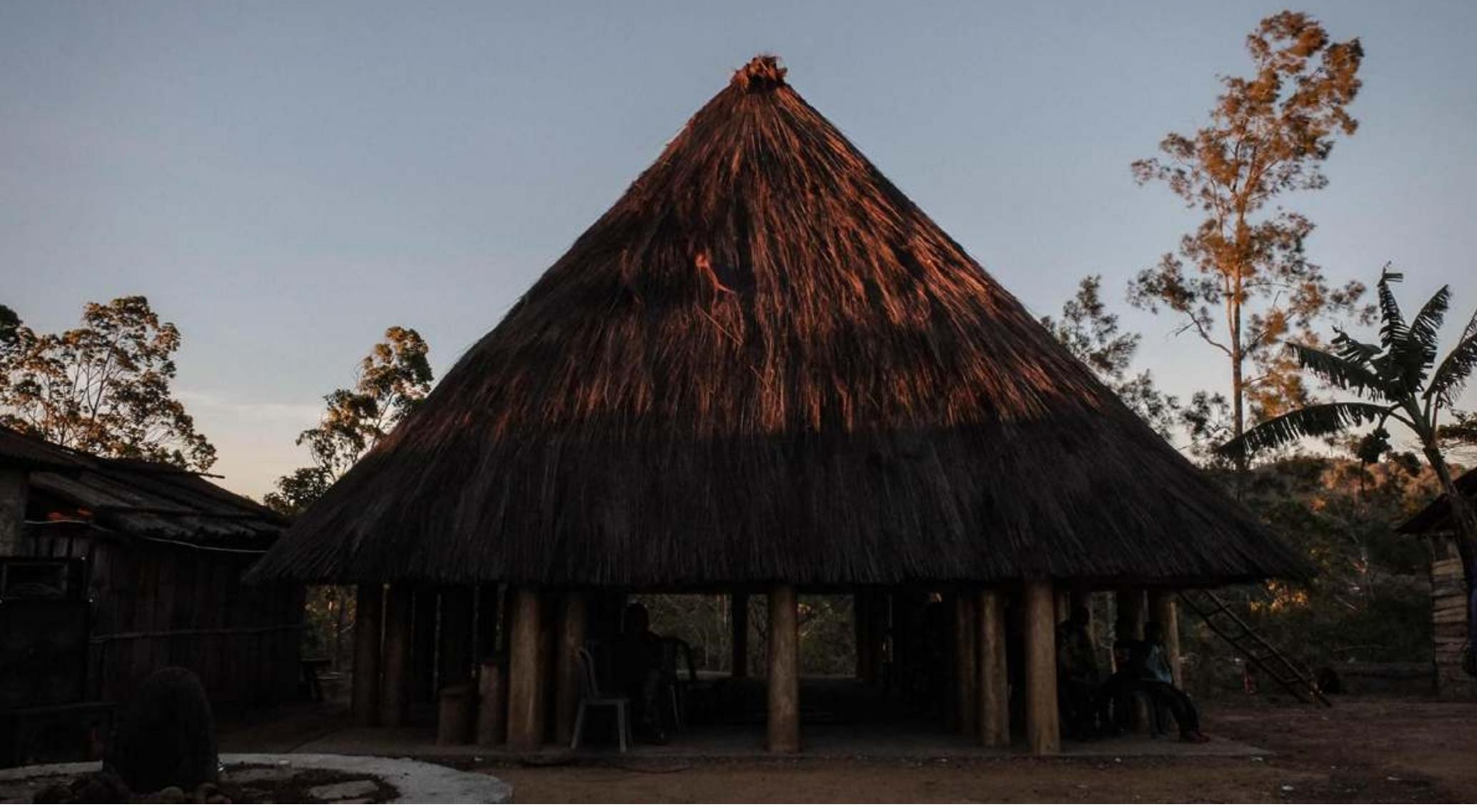

"Durante a ocupação Indonésia a Casa Sagrada Mau Suma - Rai Alas foi queimada, seus objetos sagrados roubados e seus filhos espalharam-se pelos diferentes municípios do país. No mês de julho de 2016, os membros mais velhos da "casa" se reuniram e decidiram convocar as novas gerações para reconstruir a Casa Sagrada e assim manter as crenças que vêm dos tempos dos nossos avôs... utilizamos materiais modernos como cimento e pregos, mas o importante é que foi construída de acordo com a cultura dos avôs para o encontro das novas gerações".

August Soares (Representante dos Uma-na'in). 


\section{Fotos 2 e 3}
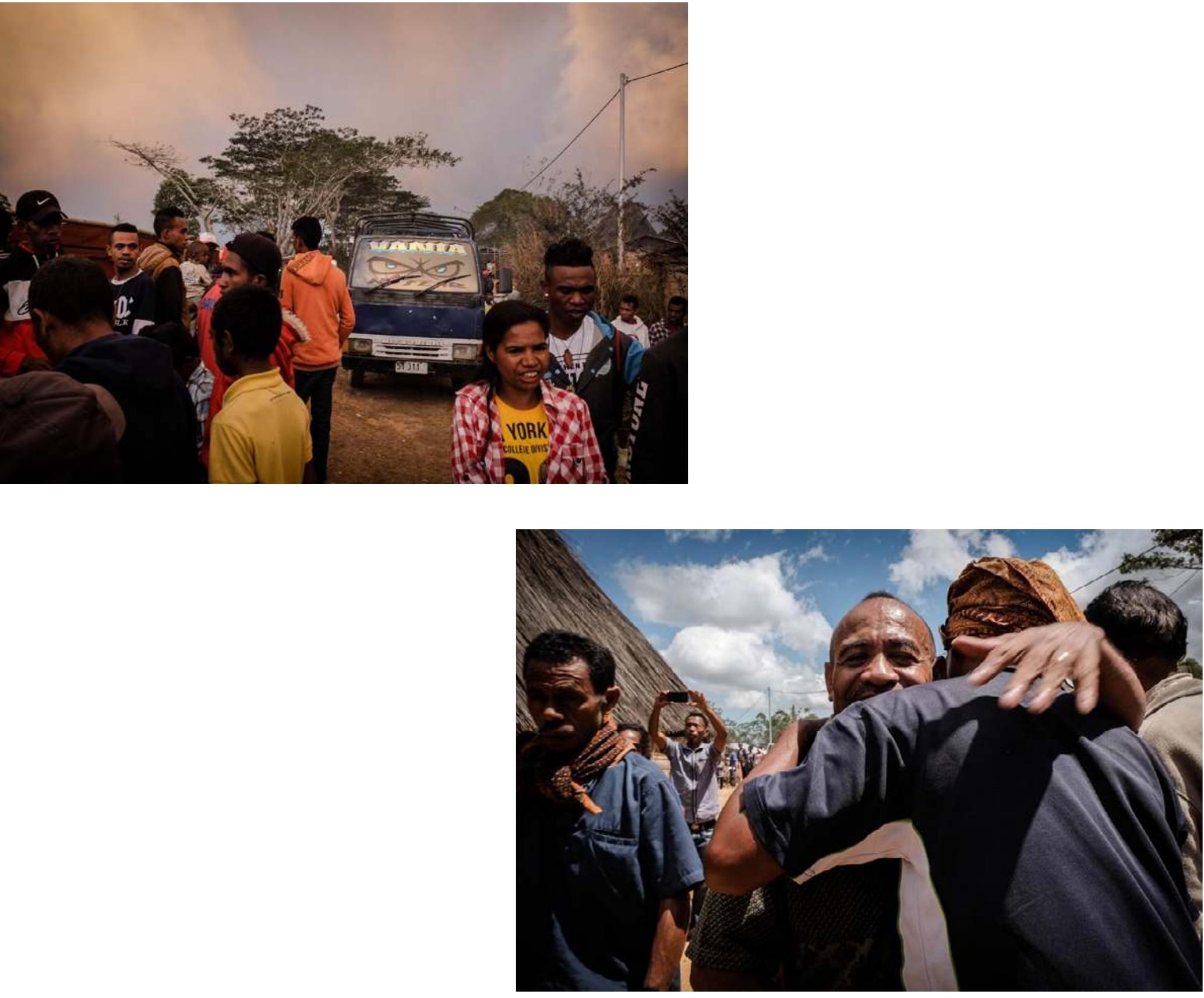

No primeiro dia do evento, pessoas vindas de diferentes aldeias do município de Ermera, de outros municípios do país e inclusive de lugares como Flores ou de Atambua, no lado indonésio da ilha, chegam à aldeia Samatrae, suco Poetete, para participar da inauguração da Casa Sagrada.

"A inauguração é uma forma para que todos os filhos desta Casa Sagrada se encontrem. Para que os umane e os mane-foun conheçam a cultura um do outro, para que em caso de ter algum problema saibam resolvê-lo".

Adozindo Trinidade (mane-foun). 


\section{Foto 4}

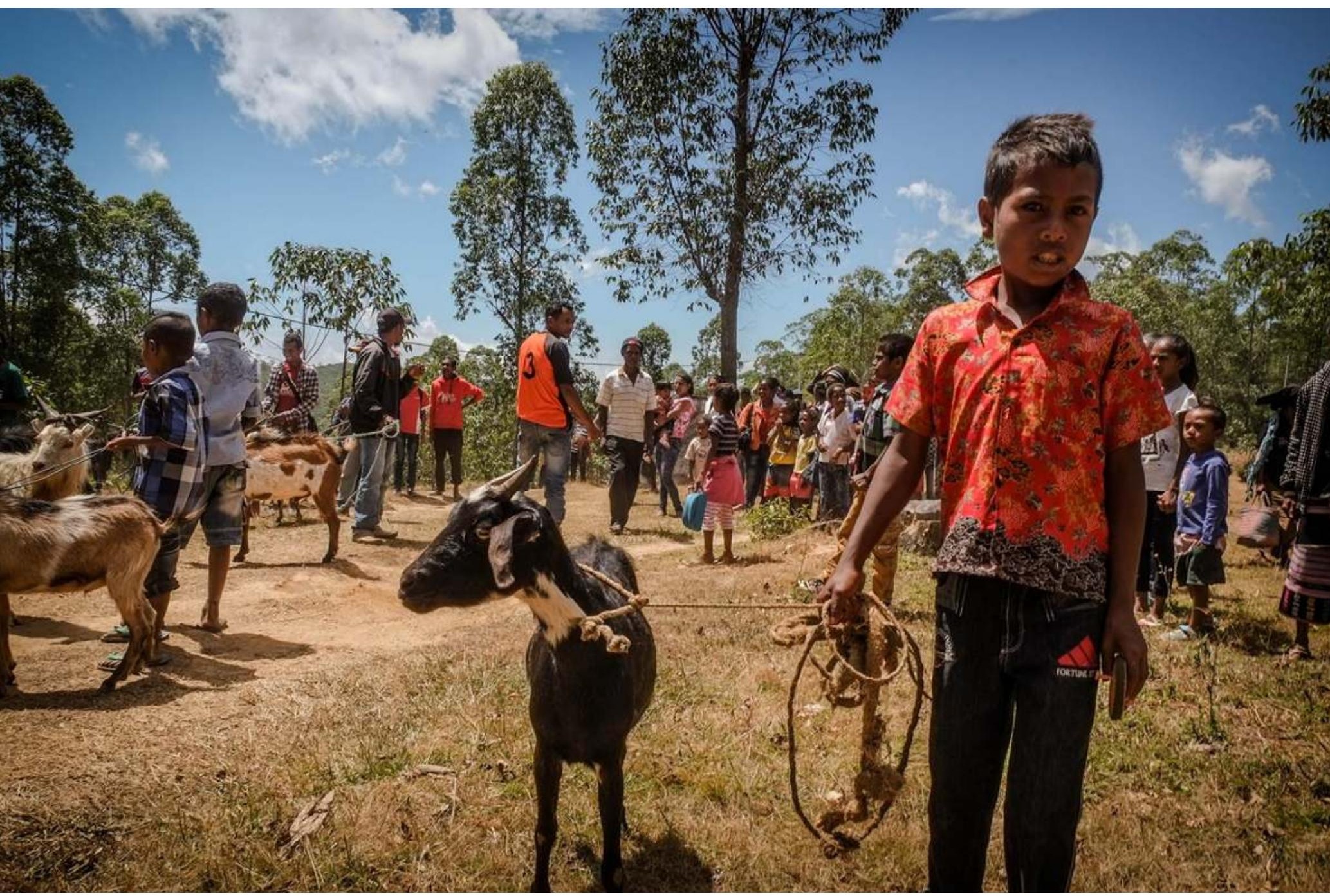

Ao redor das duas da tarde, os uma-na'in ou donos da festa autorizam a entrada ritual dos membros das casas mane-foun. A ordem de entrada dos representantes dessas é determinado pela precedência na relação com a Casa Sagrada Mau Suma. De acordo com esse princípio é a Casa Totoi Loelak, localizada a poucos metros de Mau Suma, a que inicia o ingresso.

"Venho como mane-foun, sou casado com mulher de Mau Suma e por isso devo respeitar esta Casa Sagrada. Cada pessoa que vem como mane-foun tem que entregar 10 dólares... além do dinheiro, quando é uma família pequena, de 2 ou 3 pessoas, se deve entregar um cabrito, se são mais pessoas então deve entregar mais cabritos ou um karau (búfalo)". 


\section{Foto 5}

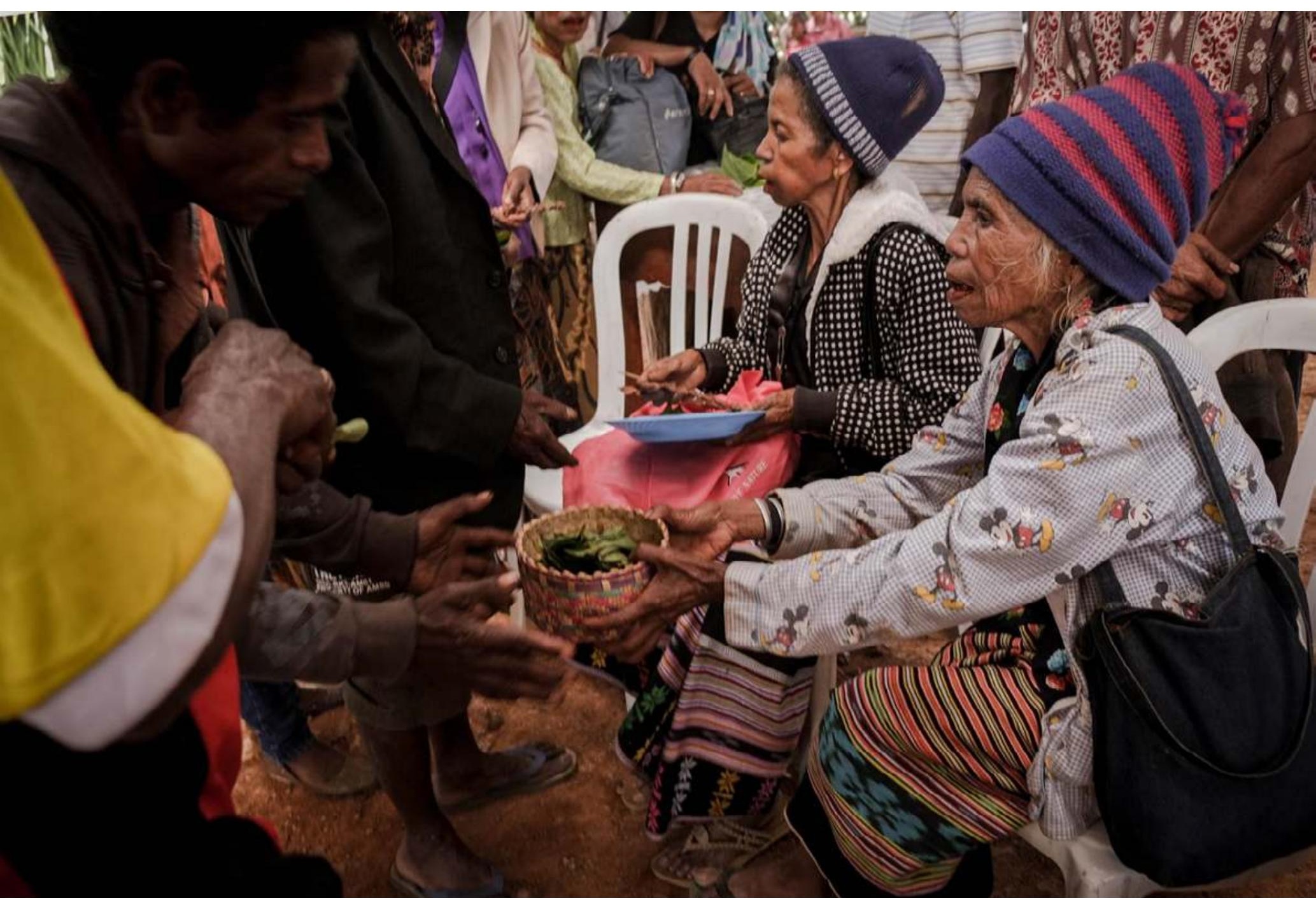

Em uma cabana construída especialmente para a primeira recepção dos convidados, duas avós da Casa Mau Suma entregam aos recém-chegados, um cesto com nozes de areca -bua- e folhas de bétel -malus-. O hábito de mascar bua-malus é generalizado no Timor-Leste sobretudo em contextos sociais - seja no encontro de duas pessoas, ou durante cerimônias - como uma forma de cumprimentar as pessoas externas à Casa Sagrada e estreitar a relação com elas (Souza, 2010).

"Entregar bua ho malus a um convidado significa que consideramos a nosso convidado na relação umane-mane-foun”.

Adozindo Trinidade 


\section{Foto 6}

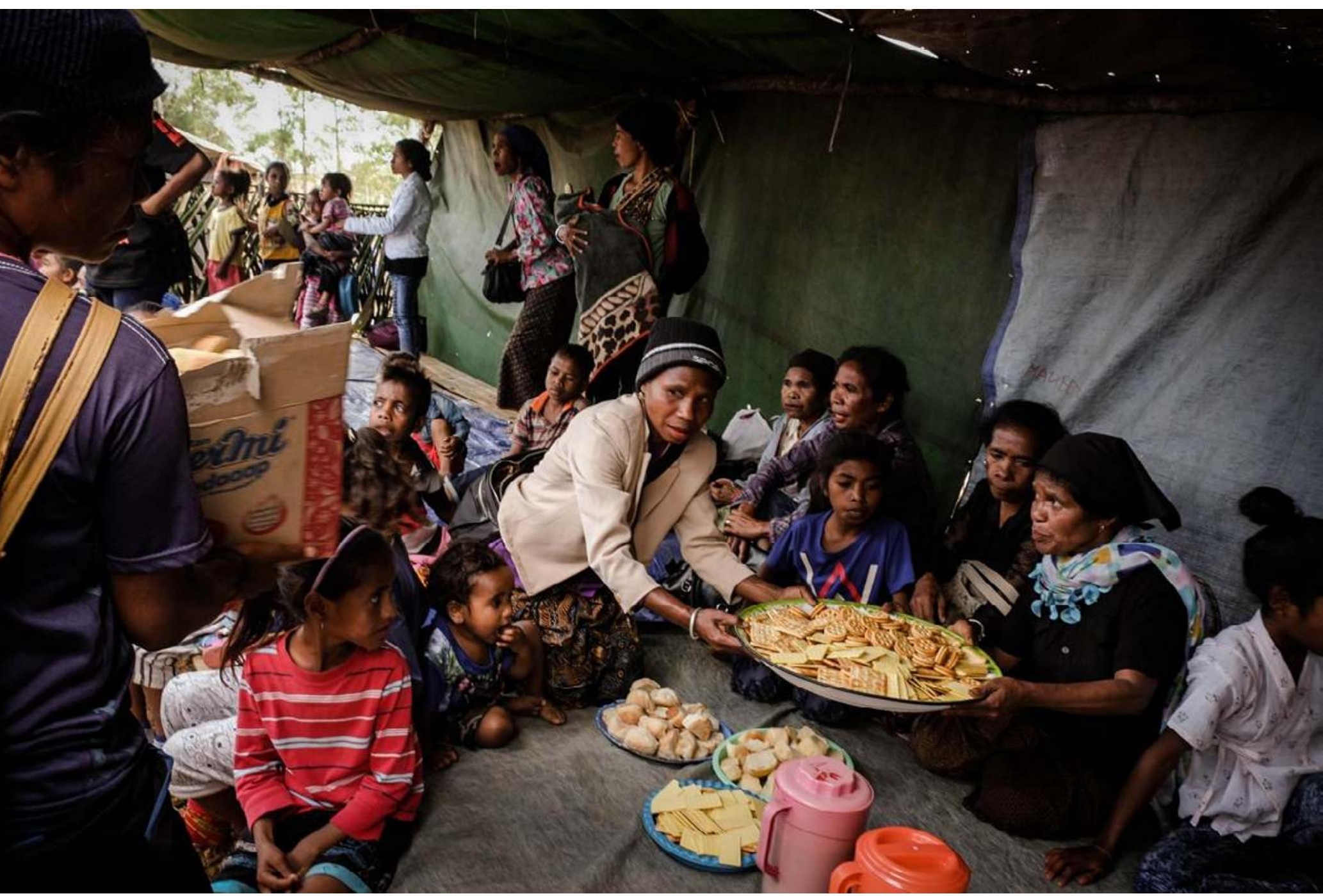

As famílias umane e mane-foun são acomodadas em cabanas de bambu e plástico construídas pelos uma-na'in. É obrigação dos primeiros brindar biscoitos e abastecer com arroz e vegetais aos grupos mane-foun. Estes últimos cozinharam nos fogões montados em cada um dos lugares assignados e devidamente identificados com o nome da "casa" à qual pertencem. 


\section{Foto 7}

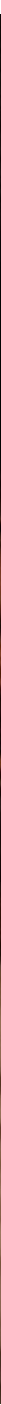

Uma comissão instalada em frente à Casa Sagrada recebe o dinheiro e leva um cuidadoso registro, que inclui também os animais, e as bebidas entregues pelos mane-foun conforme o pactuado às vésperas da festa. 


\section{Foto 8}

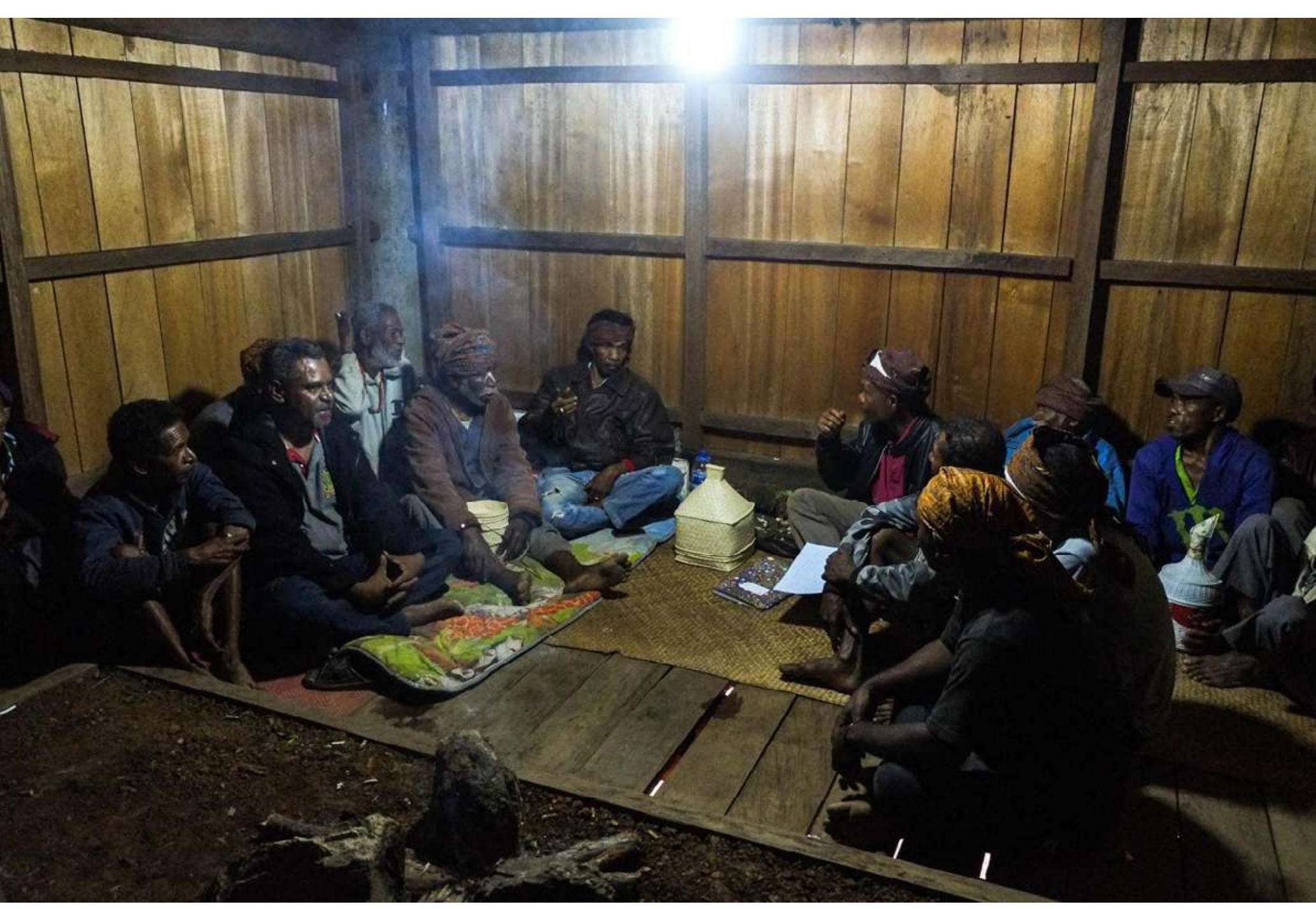

Ao redor das 9 horas da noite se produz um primeiro encontro ritual na Casa Sagrada entre os uma-na'in e representantes dos mane-foun. Durante este se faz entrega do dinheiro arrecadado, assim como do registro dos animais recebidos. Em sinal de satisfação, os uma-na'in entregaram à comissão um cesto com cervejas e pães. A finalização da jornada com esta troca é a forma de comunicar que a celebração pode continuar no dia seguinte. 


\section{Fotos 9 e 10}
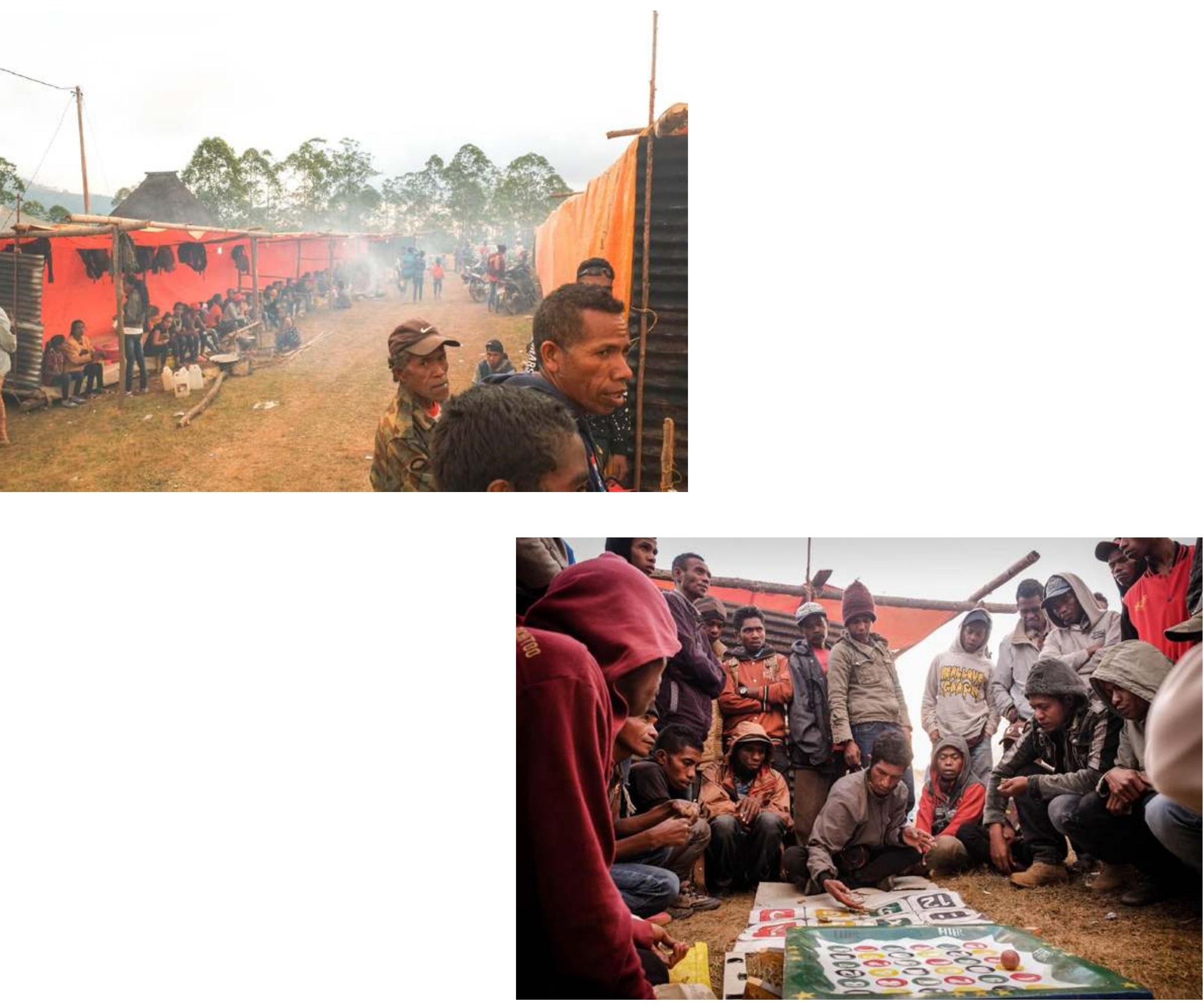

Durante os 3 ou 4 dias que pode durar a festa, os convidados permanecem a maior parte do tempo na área das cabanas para hospedagem. A partir das primeiras horas do segundo dia o bola guling - uma espécie de jogo de ruleta -, chama a atenção de alguns homens que observam e apostam pequenas quantidades de dinheiro. 


\section{Foto 11}

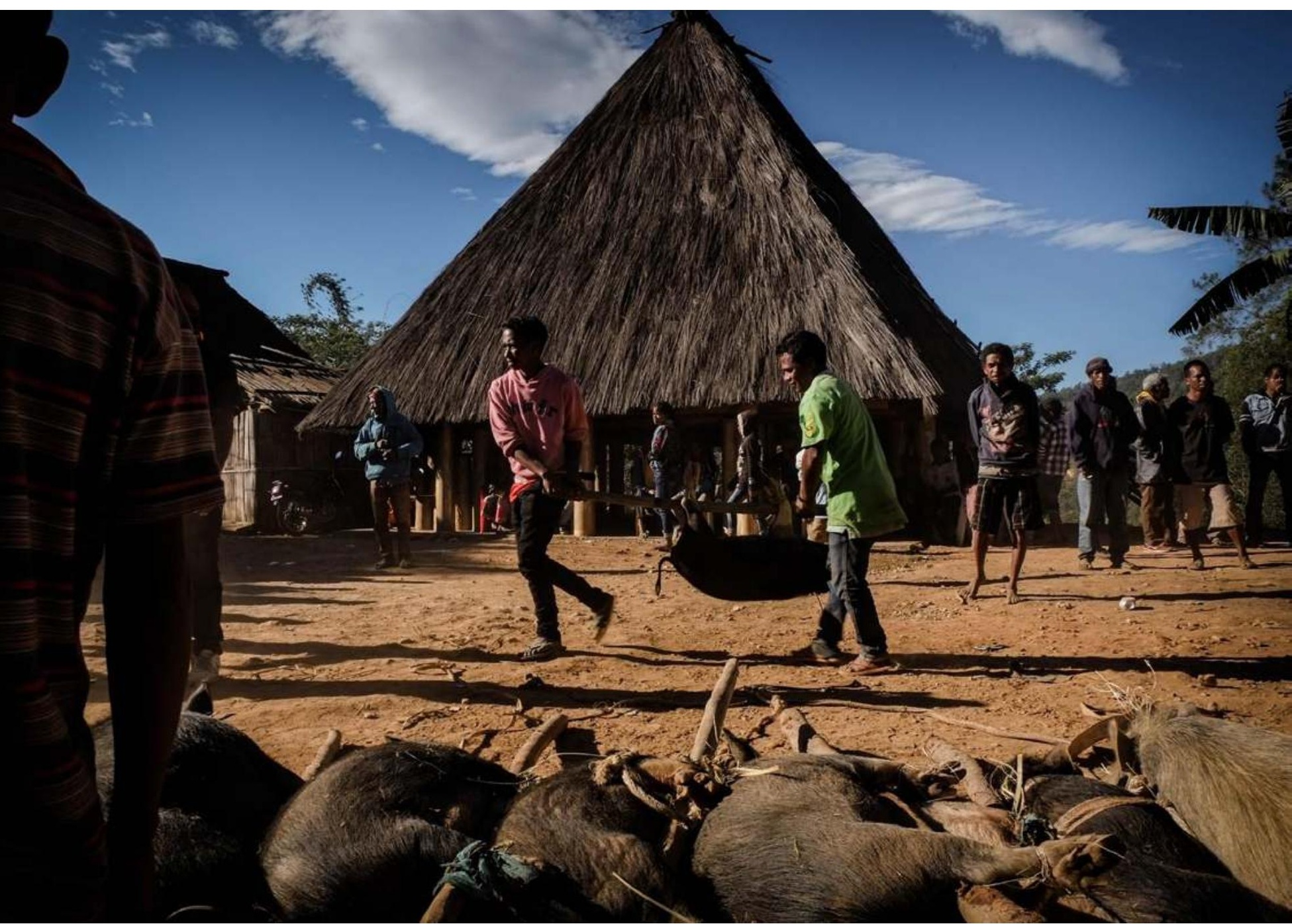

Aos umane corresponde entregar um porco de cada família que participa da inauguração. Depois do meio-dia, um total de 33 porcos são dispostos frente à Casa Sagrada e sacrificados pelos uma-na'in. 


\section{Foto 12}

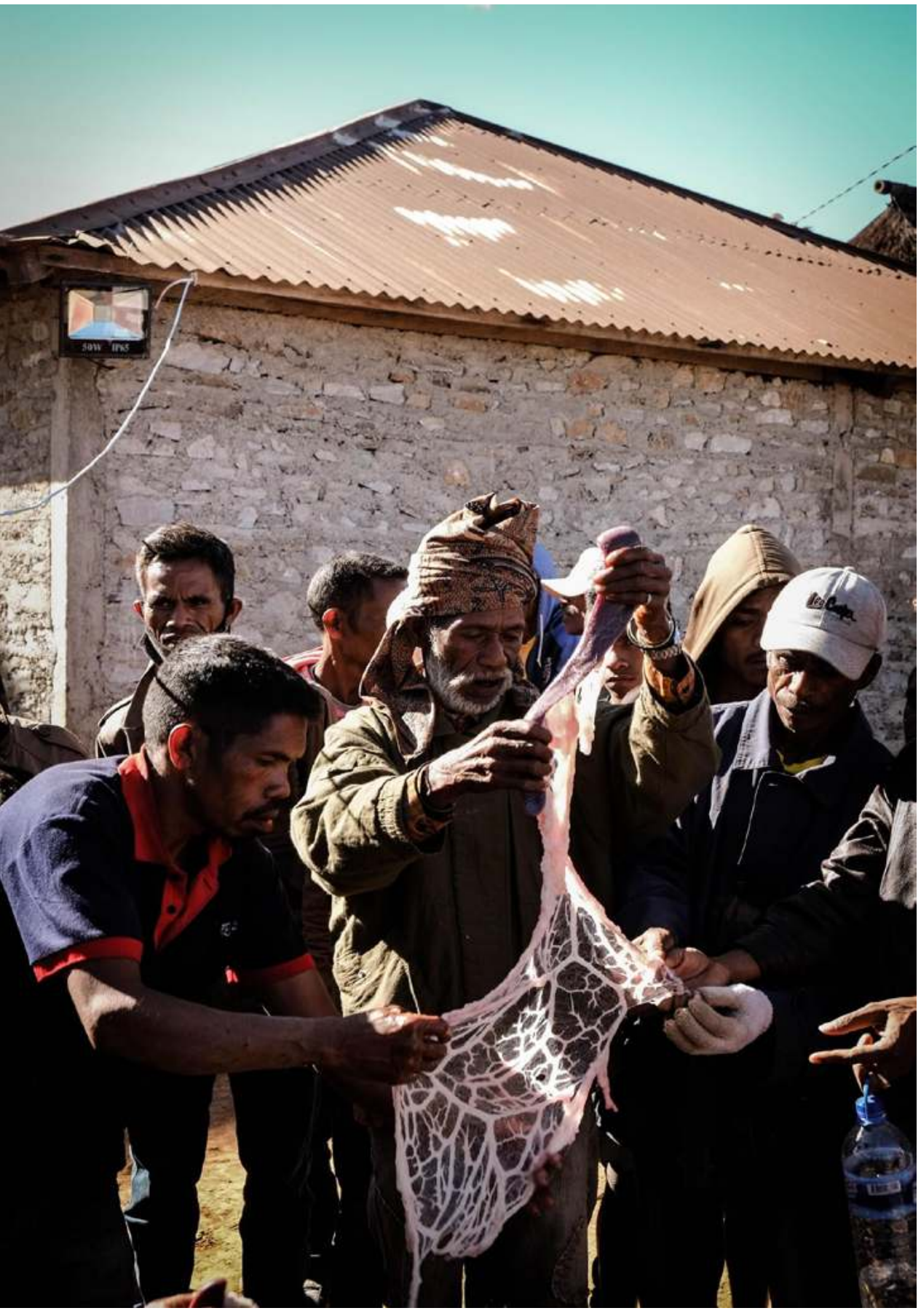

Imediatamente depois do sacrifício, as vísceras dos porcos são extraídas e levadas ao lia-na'in - a autoridade espiritual da Casa Sagrada - que, a partir de uma cuidadosa "leitura", também conhecida como urat, avalia o futuro da "casa" e dos seus filhos.

"Urat mostra o caminho indicado pela cultura... para saber se temos risco de ter doenças ou algum acidente”. 


\section{Foto 13}

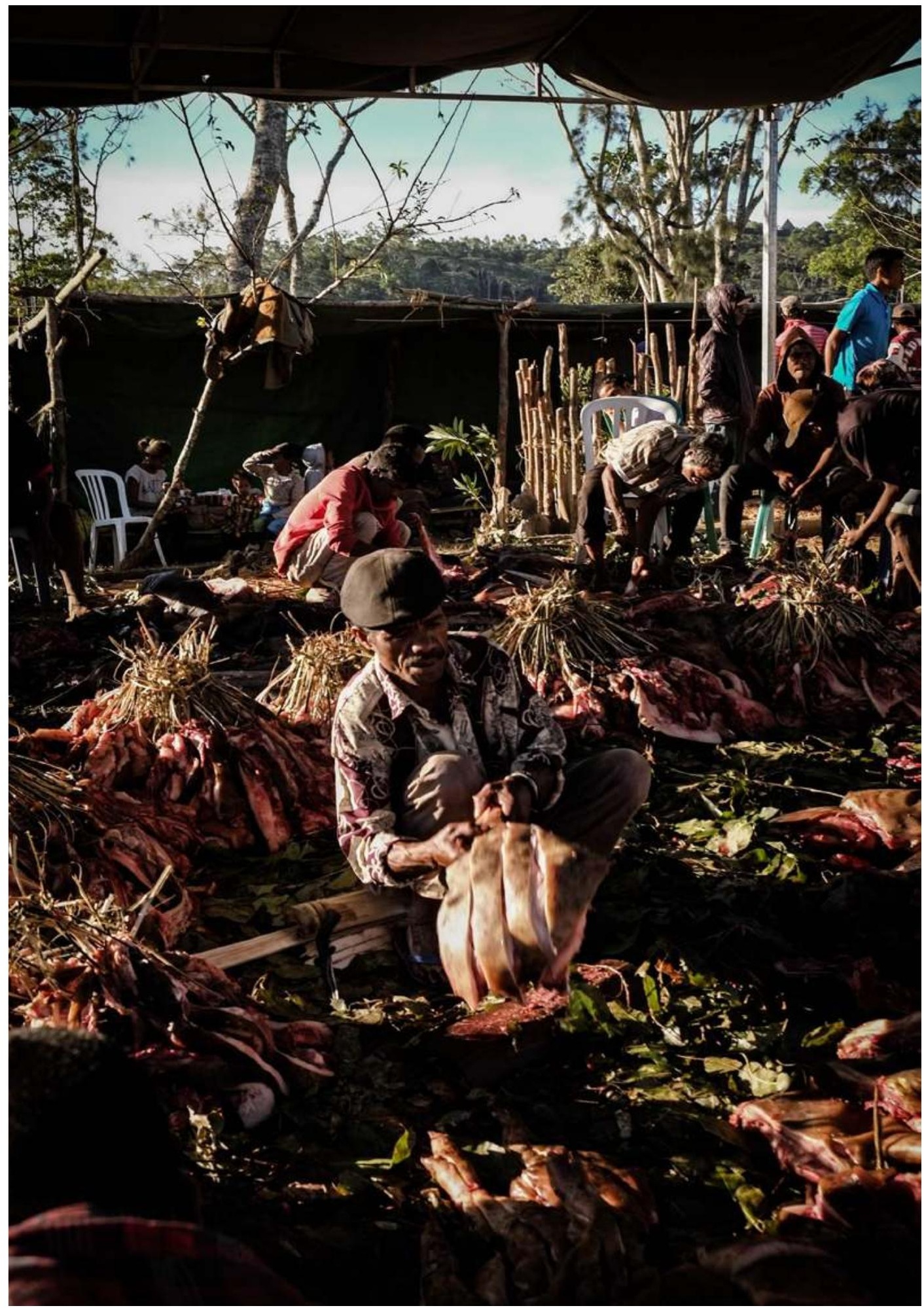

Uma intensa jornada de trabalho para preparar os porcos e retalhar a carne ocupa vários jovens e homens adultos até a madrugada do dia seguinte. 


\section{Foto 14}

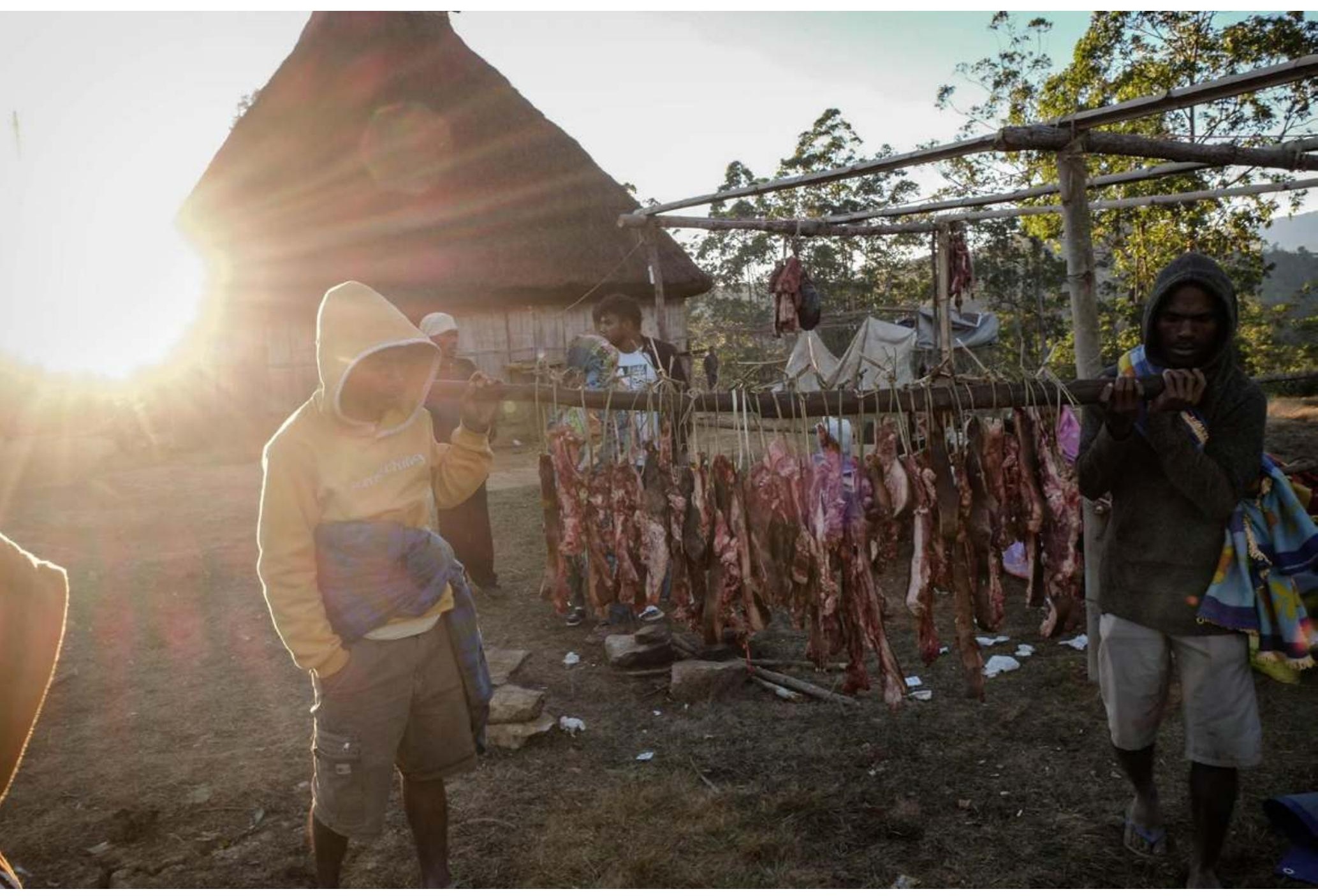

Com as primeiras luzes do terceiro dia, um grupo de jovens se aproxima até as cabanas dos mane-foun para entregar as partições de carne. Estes últimos recebem um ou dois pedaços de acordo com a quantidade de dinheiro e cabritos entregados no primeiro dia. A carne não deve ser consumida durante a festa e é levada pelos mane-foun até os seus lugares de origem. 


\section{Foto 15}

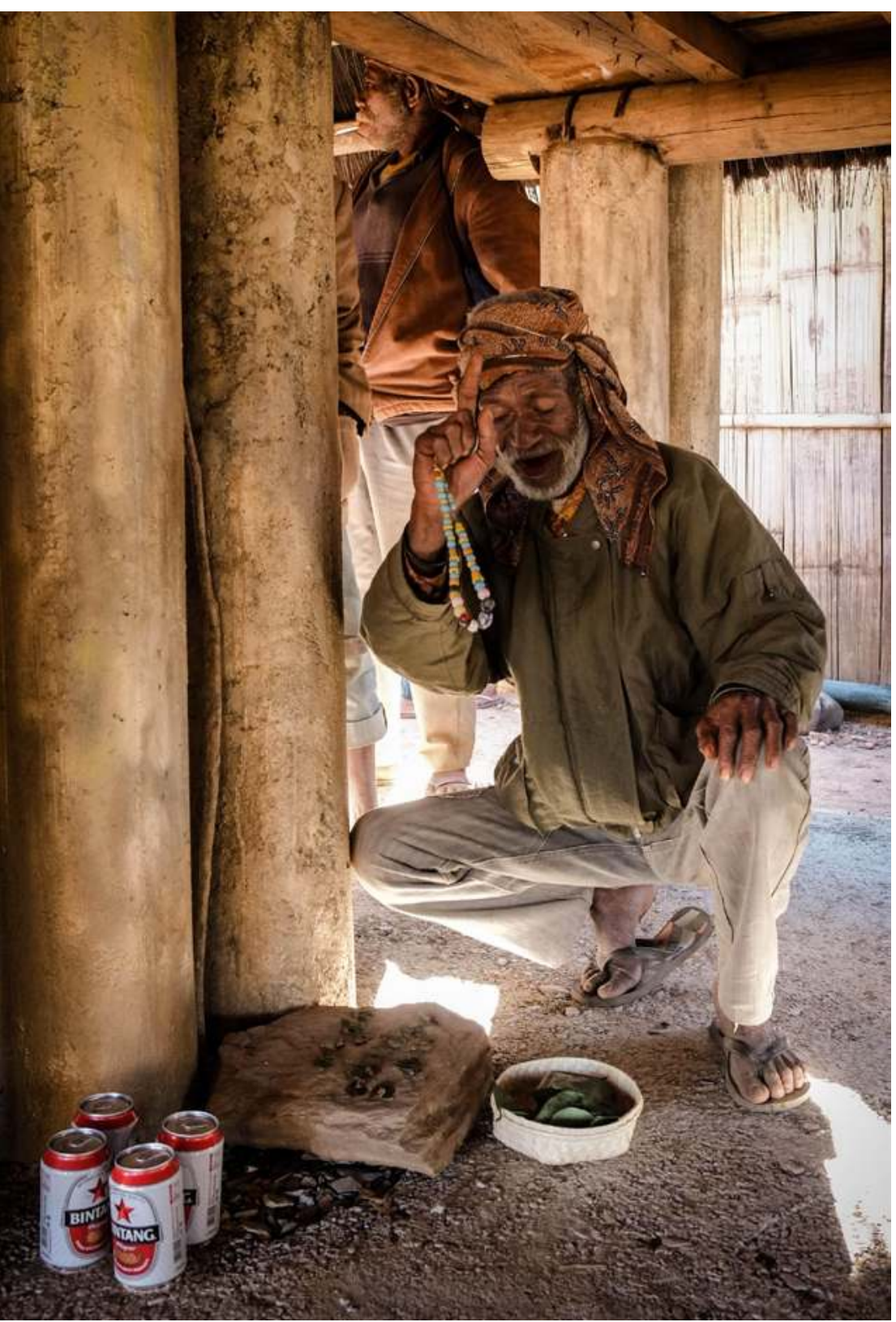

O lia-na'in ou "dono da palavra" é quem conhece e está autorizado a contar a história e genealogia da Casa Sagrada. Embora mantenha uma atitude discreta e reservada durante o evento, as ações realizadas por ele determinam o passo de uma etapa a outra na inauguração. Depois que a carne tiver sido distribuída entre os mane-foun, o lia-na'in de Mau Suma-Rai Alas realiza orações ou hamulak junto a uma das colunas da Casa Sagrada.

“Esta terra é sagrada e só o lia-na'in pode explicar sobre as coisas que está fazendo". 


\section{Foto 16}

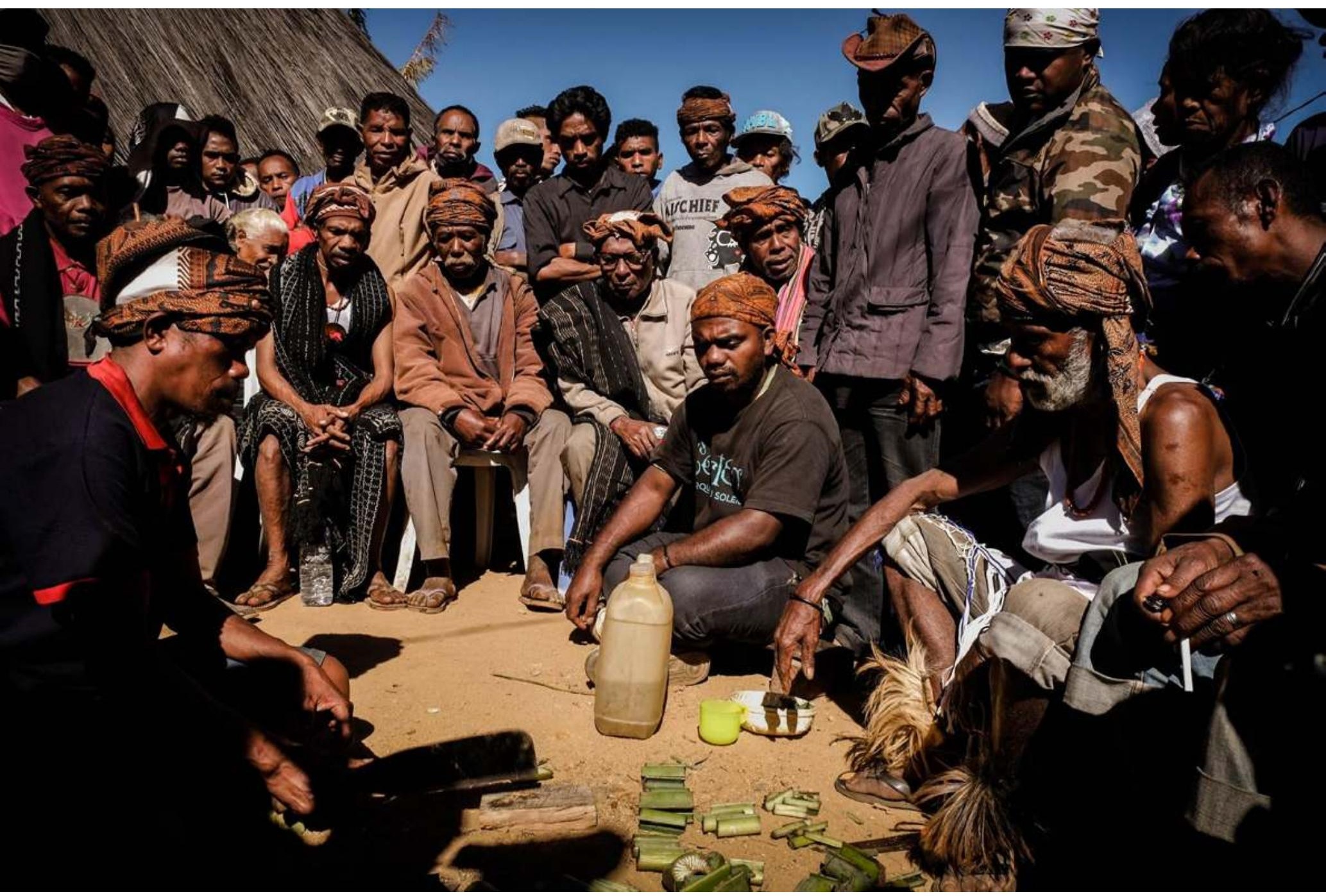

Os convidados - algumas mulheres, mas principalmente homens - agrupam-se ao redor do lia-na'in e de um ajudante para fazer Tesi hudi kai. A ação consiste na interpretação da forma como as metades de um pedaço de bananeira caem no chão no momento de serem cortadas com um facão. Cada pedaço cortado representa a relação de um dos mane-foun com a Casa Sagrada Mau Suma. A "leitura" se estende por aproximadamente duas horas. Ante um resultado negativo, o convidado deverá entregar uma moeda de um dólar ao lia-na'in, com o objetivo de neutralizar qualquer desavença.

"Quando a Natureza mostra que poderá haver algum problema no caminho de alguém, quer dizer que existiram problemas no passado, entre os avôs, que não foram resolvidos. É importante resolver agora para que não afetem a relação dos filhos da Casa Mau Suma com os seus mane-foun". 


\section{Foto 17}

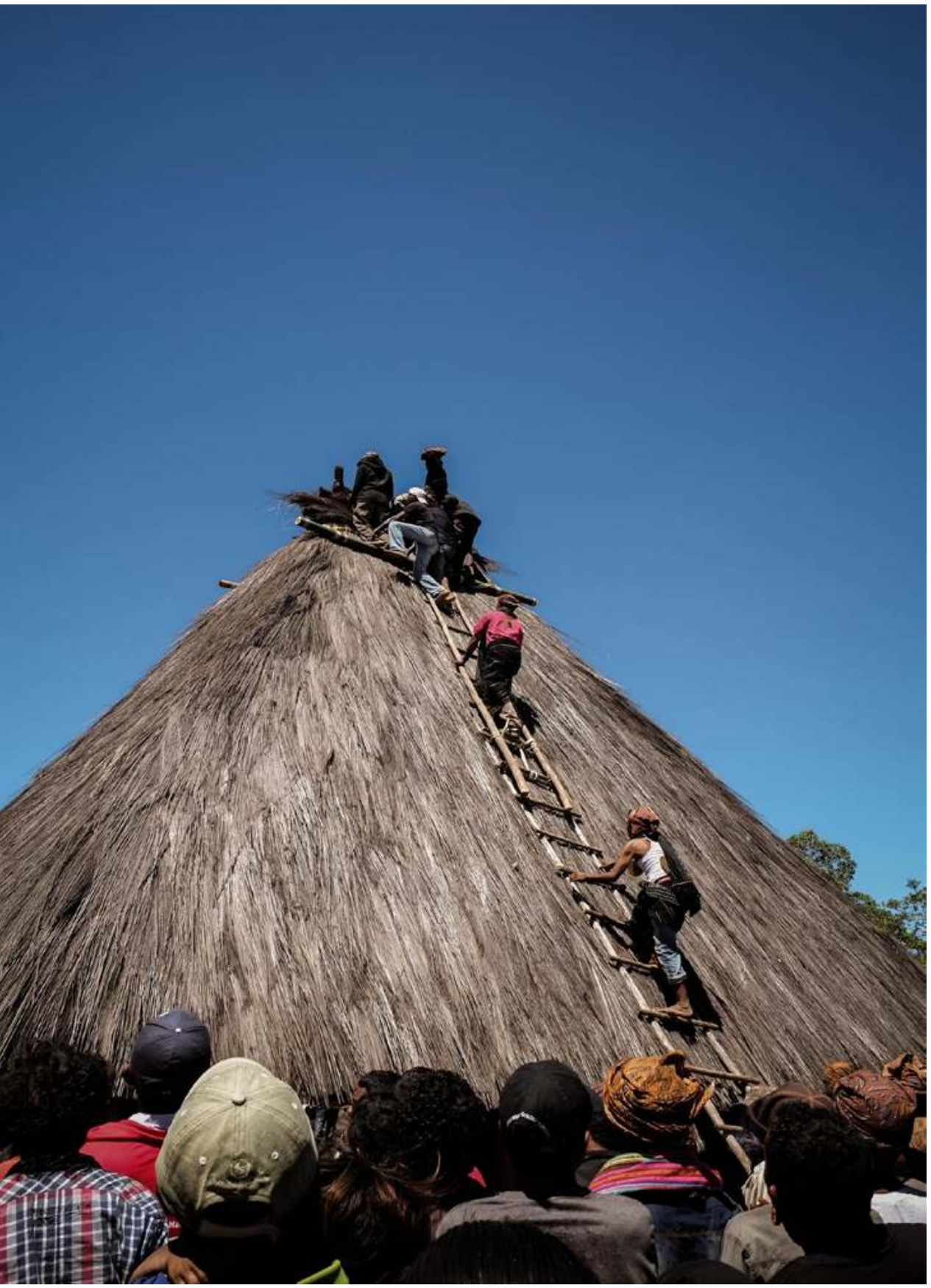

Alguns homens colocam kakuluk ou chapéu da Casa Sagrada. Ao ato assistem autoridades locais do município que nesta altura se somam ao evento. Com este ato se dá por inaugurada oficialmente a Casa Sagrada.

"A partir desse momento, os convidados, tanto umane como mane-foun, podem entrar na Casa Sagrada para receber o Matak Malirin... assim como na Igreja o Padre dá bênção, a Natureza entrega Matak Malirin "’.

1 Expressão do tétum térik cuja tradução literal ao português é "o verde e o frio". Metaforicamente representa a ideia de paz, prosperidade, boa saúde e proteção contra a má sorte. O objetivo final dos rituais é receber matak-malirin, a qual é distribuída no final do evento nas formas de bua-malus, milho, arroz e carne (Trinidade, 2014, p. 8). 


\section{Foto 18}

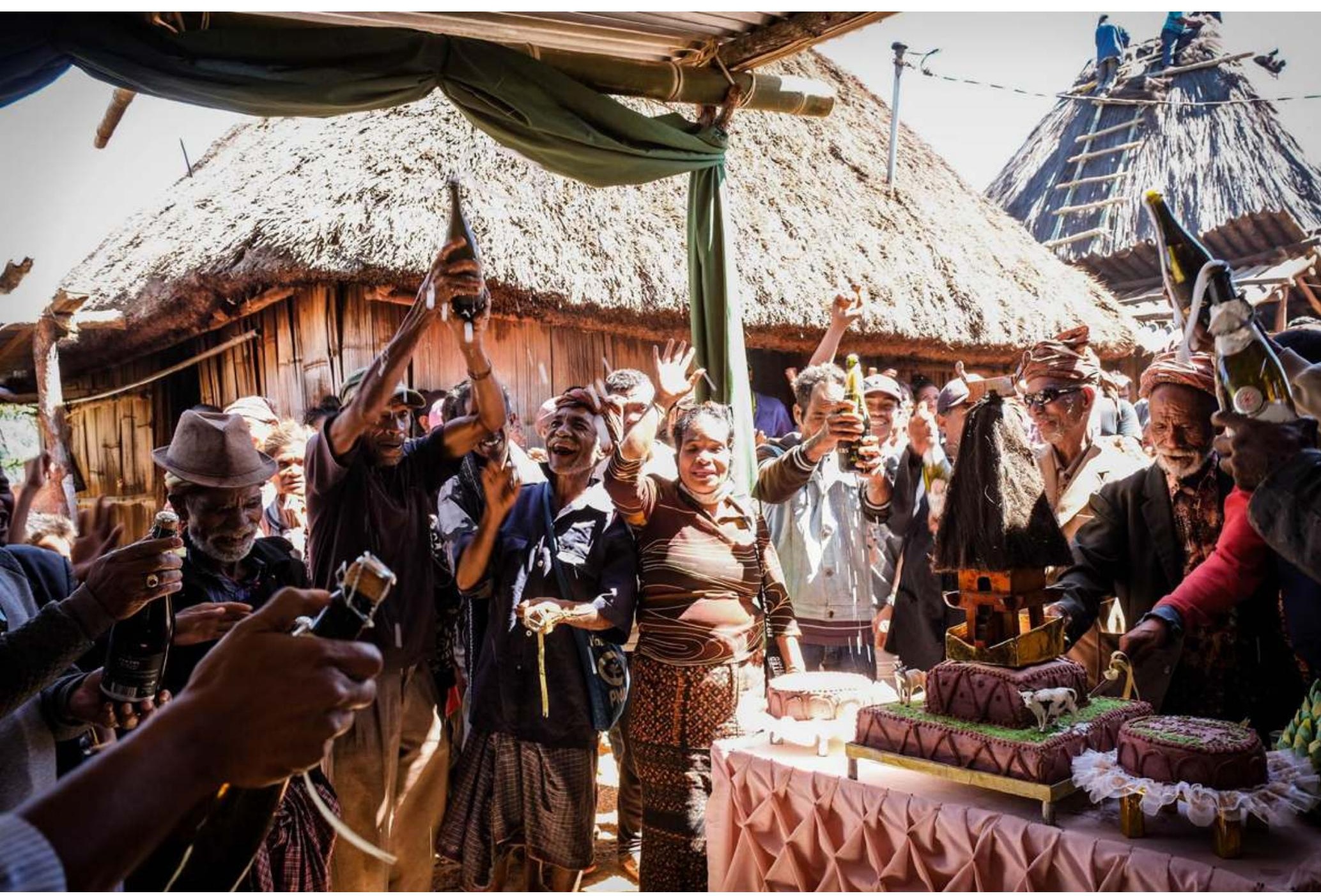

Com espumante, bolo e bufê - itens associados às comemorações em contextos urbanos - começa uma grande festa que também inclui músicos tocando ao vivo. O protocolo e moderação mantida pelos convidados durante os 3 dias anteriores se transforma rapidamente em ambiente festivo e animação. $\mathrm{O}$ baile, que se estende até o amanhecer do quarto dia, integra e desfaz a divisão entre os uma-na'in, umane e mane-foun. 


\section{Agradecimentos}

Aos filhos das Casas Sagradas Mau Suma e Totoi Loelak na aldeia Samatrae, pelo acolhimento. A colaboração de Alvaro Vasconcelos foi determinante na conformação da rede de contatos que fizeram possível a pesquisa no município de Ermera. O diálogo com Renata Nogueira durante o trabalho de campo permitiu vislumbrar a importância dos rituais e das Casas Sagradas na relação das populações timorenses com a terra. Os colegas do Laboratório de Economias e Globalizações - LEEG, da Universidade de Brasília, e Marcela Vallejo comentaram e fizeram importantes aportes à primeira versão do ensaio. Agradeço especialmente a Alberto Fidalgo pela leitura cuidadosa e as indicações bibliográficas. Sou grato aos dois pareceristas anônimos pelas generosas contribuições a este trabalho, assim como às editoras(es) do Anuário Antropológico.

\section{Referências}

BARNES, Susana. Nation-building and the Resurgence of Custom. In: GRENFELL, Damian et al. Nation-building across urban and rural Timor-Leste. Conference Report. Dili: Globalism Research Centre; RMIT University, 2010.

BARNES, Susana. Customary Renewal and the Pursuit of Power and Prosperity in Post-Occupation East Timor: A Case-Study from Babulo, Uato-Lari. Tese (Doutorado em Antropologia) - Monash University, Melbourne, 2016.

BROWN, Anne. Security, Development and the Nation-Building Agenda: East Timor. Conflict, Security and Development, v. 9, p. 141-164, 2009.

CARSTEN, Janet; HUGH-JONES, Stephen. Introduction. In: CARSTEN, Janet; HUGH-JONES, Stephen (Orgs.). About the House: Lévi-Strauss and Beyond. Cambridge: Cambridge University Press, 1995.

EDWARDS, Elizabeth. Tracing Photography. In: BANKS, Marcus; RUBY, Jay (Eds.). Made to Be Seen: Perspectives on the History of Visual Anthropology. Chicago: University of Chicago Press, 2012.

FIDALGO-CASTRO, Alberto. Dinámicas políticas y económicas en el dominio ritual y la vida cotidiana en Timor Oriental: Estudios de caso desde la aldea de Faulara. Tese (Doutorado em Antropologia Social) - Universidade da Coruña, Ferrol, 2015.

FOX, James. The Flow of Life: essays on Eastern Indonesia. Cambridge: Harvard University Press, 1980.

FOX, James. Comparative perspectives on Austronesian houses: An introductory essay. In: FOX, James (Ed.). Inside Austronesian houses: Perspectives on domestic designs for living. Canberra: The Australian National University, 1993. 
Carlos Andrés Oviedo

GÁRATE CASTRO, Luis Alberto; ASSIS, Cecília. Património Cultural de Timor-Leste. As Uma Lulik Do Distrito de Ainaro. Ferrol: Secretaria de Estado da Cultura da República Democrática de Timor-Leste, 2010.

HICKS, David. Community and Nation-State in East Timor. Anthropology Today, v. 23, p. 13-16, 2007.

McWILLIAM, Andrew. Houses of Resistance in East Timor: Structuring Sociality in the New Nation. Anthropological Forum, v. 15, p. 27-44, 2005.

McWILLIAM, Andrew; TRAUBE, Elizabeth G. Introduction. In: McWILLIAM, Andrew; TRAUBE, Elizabeth (Eds.). Land and Life in Timor-Leste: Ethnographic Essays. Canberra: The Australian National University Press, 2011.

NOGUEIRA DA SILVA, Renata. Tamba sá sae foho? Alargamento da vida social das Uma Lulik em Timor-Leste. In: SILVA, Kelly; SIMIÃO, Daniel; OLIVEIRA, Ana Carolina; TAM, Therese; FIDALGO-CASTRO, Alberto (Orgs.). Rupturas, continuidades e novas sinteses em Timor-Leste: Anais da 1a Conferência TLSA-BR; Schisms, Continuity and New Synthesis in Timor-Leste: Proceedings of the 1st TLSA-BR Conference. Brasília; Belo Horizonte: Timor-Leste Studies Association; Casa Apoema, 2019.

OVIEDO, Carlos Andrés. Uses of kultura in land registration in Timor-Leste: Reflections from the municipality of Ermera. In: SILVA, Kelly (Ed.). Performing Modernities: pedagogies and technologies in the making of contemporary Timor-Leste. Rio de Janeiro: ABA Publicações, 2020.

PEIRANO, Mariza. A análise antropológica de rituais. Série Antropologia, n. 270, v. 30, 2000.

ROMANÓ, Henrique. Encounters with justices: Transpositions and subversions of modernity in contemporary East Timorese legal practices. In: SILVA, Kelly (Ed.). Performing Modernities: pedagogies and technologies in the making of contemporary Timor-Leste. Rio de Janeiro: ABA Publicações, 2020.

SIMIÃO, Daniel. Uma Lisan Bakal Mausoko Mautete (documentário). 2009. Disponível em: https://www.youtube.com/watch?v=f760nsBQ1_Y\&t. Acesso em: 2 mar. 2021.

SIMIÃO, Daniel. Pás ho Dame (documentário). IRIS - Laboratório de Imagem e Registro de Interações Sociais, Universidade de Brasília. 2015. Disponível em: https://www. youtube.com/watch?v=-QT1A_b_Hq8. Acesso em: 2 mar. 2021.

SIMIÃO, Daniel. Os três patrões: a habilidade negocial das lia e o peso da kultura. E-cadernos CES, v. 33, p. 9-32, 2020.

SOUSA, Lúcio. This is the beginning of the relationship: Material supports of cultural translations. In: SEIXAS, Paulo (Ed.). Translation, society and politics in Timor-Leste. Porto: Universidade Fernando Pessoa, 2010.

TRINIDADE, Jose Josh. Matak-malirin, Tempu Rai-diak and Halerik: Expressions of what Timorese Longed for in Life. In: LONEY, Hannah; SILVA, Antero B. da; CANAS, Nuno; DA COSTA, Alarico; FERNANDES, Clinton (Eds.). Buka hatene / Compreender/Mengerti / Understanding Timor-Leste 2013. v. II. Timor-Leste Studies Association, 2014

TURNER, Victor. The Forest of Symbols. Ithaca: Cornell University Press, 1967. 